\title{
Bir Küçük Adanın Büyük Turizm Başarısı: Camiguin Adası Örneği*
}

\author{
Great Tourism Success of A Small Island: The Case of Camiguin Island
}

\section{Emin ATASOY}

Prof. Dr., Bursa Uludağ Üniversitesi, Eğitim Fakültesi,

Türkçe ve Sosyal Bilimler Eğitimi Bölümü,

eatasoy@uludag.edu.tr

https://orcid.org/0000-0002-6073-6461

\section{Maria Victoria Ortega ESPALDON}

Prof. Dr., University of the Philippines Los Banos,

College of Human Ecology,

mariavictoriaespaldon@gmail.com

https://orcid.org/0000-0001-6481-8328
Makale Başvuru Tarihi: 06.08.2020

Makale Kabul Tarihi: 25.08.2020

Makale Türü: Araştırma Makalesi

\section{ÖZET}

Anahtar

Kelimeler:

Filipin Adalarl,

Camiguin Adast,

Filipinler

Cumhuriyeti,

Turizm,

Keywords:
Philippine Islands,
Camiguin Island,
Philippines
Republic,
Tourism,

* Bu çalışma "2019-Yurt Dışı Doktora Sonrası Araştırma Burs Programı” kapsamında TÜBİTAK - BİDEB tarafindan 2020 yılında kabul edilen ve Prof. Dr. Emin ATASOY tarafından yürütülen "Siyasi, İktisadi ve Beşeri Coğrafya Perspektifinden Filipinler Cumhuriyeti ve Türkiye-Filipinler Etkileşimi”" başlıklı araştırma programının bilimsel çıktılarından biridir.

Mindanao adasinın kuzeyinde ve Bohol denizinin güneyinde yer alan Camiguin adası Filipinlerin en önemli ve en ilginç 25 turizm merkezinden biridir. Çok sayıda volkanik dă̆, lagün gölü, kaplıca, mă̆ara ve ilginç şelale barındıran ada dünyanın en iyi 10 dalgıçlık merkezlerinden biri olarak seçilmiștir. Camiguin adasının en büyük turizm avantajlarından birisi küçük yüzölçümüne sahip olmasına rağmen çok çeşitli turizm olanakları, çok sayıda kaliteli konaklama tesisi ve zengin rekreasyon faaliyetlerini aynı anda sunabilmesidir. Bu çalışmada Filipinler Cumhuriyeti'nde ve Mindanao Adalar Grubu'nda yer alan Camiguin adasinın başlıca coğrafi özellikleri ve turizm potansiyeli irdelenmiş̧tir. Bu araştırmada adanın coğrafi konumu, doğal ve beşeri özellikleri tartışıldı̆̆ gibi turizm çekicilikleri ve başlıca turizm kaynakları da kısaca ele alınmıştır. Adanın başlıca plajları, kentleri, şelaleleri, mağaraları, volkanları, inanç merkezleri ve tarihsel-kültürel çekicilikleri irdelenerek adanın turizm potansiyeli resmedilmeye çalışılmıştır. Çalışmanın sonuç kısmında, Camiguin adasının en büyük turizm avantajları nelerdir sorusuna yanıt aranmıştır.

\section{ABSTRACT}

The Camiguin Island located to the north of the Mindanao Island and to the south of the Bohol Sea, is one of the 25 most significant and interesting tourist destinations in the Philippines. The island, which possesses many volcanic mountains, lagoon lakes, hot springs, caves and interesting waterfalls, has been nominated as one of the top 10 diving centers in the world. One of the major tourism advantages of the Camiguin Island is that despite its small surface area, it offers a wide range of tourism opportunities, ample quality accommodation facilities and rich recreational activities at the same time. In this study, the main geographical features and tourism potential of the Camiguin Island, which is located in the Republic of Philippines and Mindanao Islands Group, have been examined. In the present study, the geographical location of the island, its natural and human characteristics have been discussed; besides, the touristic attractions and major tourism resources have been briefly discussed. We tried to identify the tourism potential of the island by examining the main beaches, cities, waterfalls, caves, volcanoes, belief centers and historical-cultural attractions. In the conclusion part of the study, the answer to the question of what are the biggest tourism advantages of the Camiguin Island has been sought. 


\section{GíRiş}

Asya kıtasının en kalabalık Katolik nüfuslu ülkesi olan Filipinler, aynı zamanda gezegenimizin en çok adaya sahip devletlerinden biridir. İtalya büyüklügünde bir ülke olan Filipinler Cumhuriyeti’nin toplam alanı 298170 $\mathrm{km}^{2}$ olup, bunlardan $105000 \mathrm{~km}^{2}$,yi Luzon adası ve $95000 \mathrm{~km}^{2}$,yi Mindanao adası oluşturmaktadır. Yüzölçümü bakımından Filipinler 105 milyonu aşan nüfusuyla dünyanın en kalabalık nüfuslu 12. ülkesidir ve yüzölçümü bakımından da dünya sıralamasında 71'inci en büyük ülke olarak yer almaktadır.

Coğrafi konum olarak Filipin adalarının tamamı hem gezegenimizin kuzey ve doğu yarımküresinde, hem de Asya kıtasının doğusunda ve Büyük Okyanusun batısında yer almaktadırlar. Ülkenin kuzey-güney istikametindeki uzunluğu yaklaşık 1850 km olup, doğu-batı istikametindeki maksimum genişliği ise 1100 km'ye kadar ulaşmaktadır ${ }^{1}$.

Harita 1. Filipinler Cumhuriyeti Lokasyon Haritası

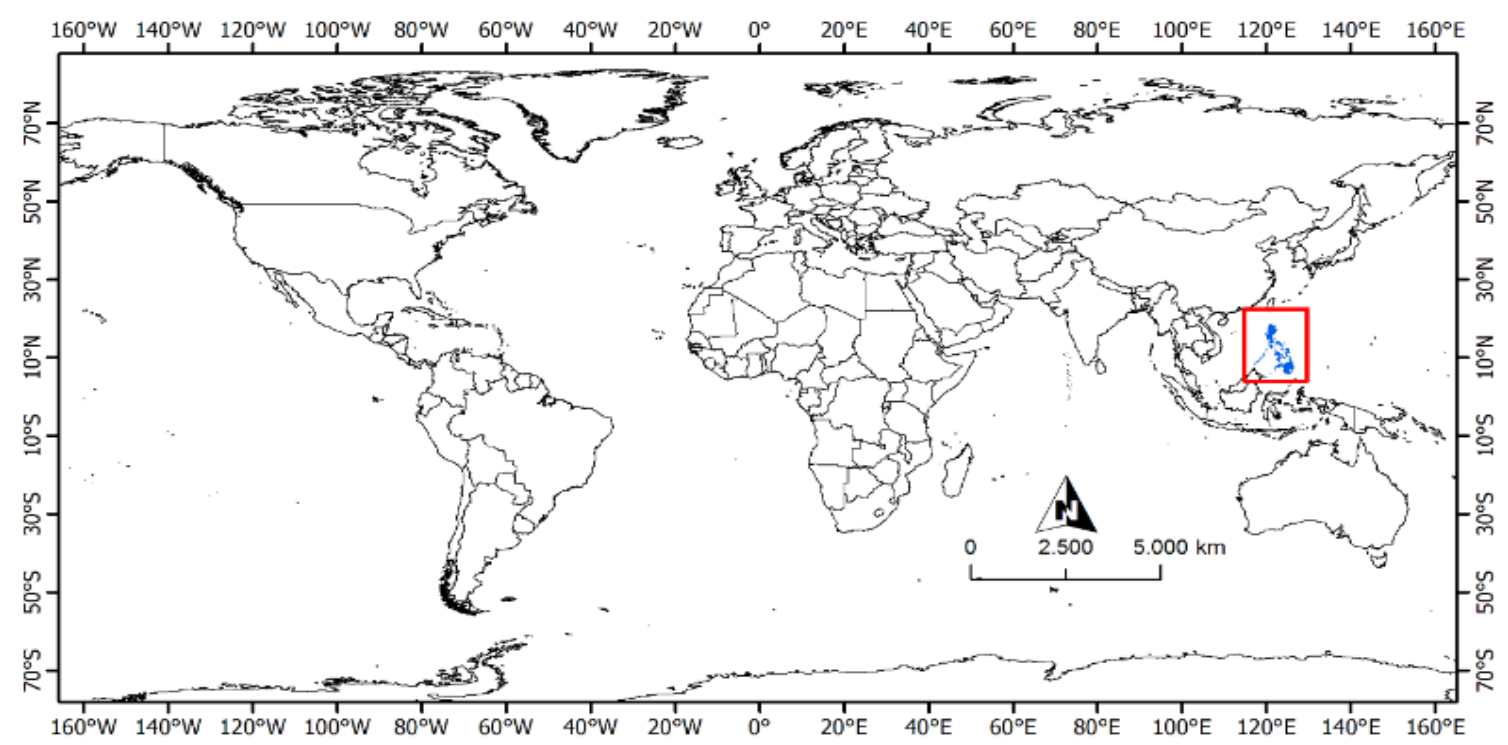

Filipin takımadaları kuzeyden ve batıdan Güney Çin Denizi, doğudan Filipinler Denizi, güneyden Sulavesi Denizi, güneybatıdan da Sulu Denizi ile çevrilidir. Bir başka anlatımla bir Uzakdoğu devleti olarak Filipinler Cumhuriyeti dört farklı denizle çevrili olup tüm bu denizler Büyük Okyanus (Pasifik Okyanusu) havzasının bir parçasıdır (Harita1). Ayrıca Filipinler'in toplam kıyı uzunluğu 36289 kilometre olup dünyanın en uzun kıyı şeridine sahip ilk 5. ülkesinden biridir.

Filipin adaları dünyanın en büyük takımadalarını oluşturan Malay Takımadalarının bir parçasıdırlar. Ülke sınırları içinde 7107 'den fazla ada ve adacık yer almaktadır, fakat bunlardan yaklaşık 2000'inde insan yaşamaktadır. Filipinler'de binlerce adanın birbirinden uzak ve dağınık olarak yer almaları bir yandan ulaşım, ticaret ve haberleşme gibi temel iktisadi faaliyetleri zorlaştırmış ve ekonomik maliyetleri arttırmış, diğer yandan da siyasi, kültürel ve ulusal birliği zedelemiştir. Bugün bölgeler ve eyaletler arasında refah düzeyi, kültürel yapı ve gelişmişlik bakımından önemli farklılıklar varsa bu jeopolitik ve jeoekonomik sonuç binlerce dağınık ve parçalanmış adanın Filipinler'e sunduğu coğrafi mirasın hüzünlü faturası olduğu söylenebilir.

Filipin adaları coğrafi konuma göre 3 büyük gruba ayrılır. Filipinler Cumhuriyeti bayrağında yer alan üç yıldız aslında bu 3 ada grubunu temsil etmektedir. Ülkenin kuzey bölgelerindeki adalar "Luzon Grubu Adalarında", orta kesimdeki adalar "Visayas Grubu Adalarında", ülkenin güney kesimlerindeki adalar da "Mindanao ve Sulu Takım Adaları" grubunda yer almaktadırlar. ${ }^{2}$ Bu çalışmada "Mindanao ve Sulu Takım Adaları" grubunda yer alan Camiguin adasının coğrafi yapısı ve turizm potansiyeli irdelenmiştir.

1 Daha detaylı bilgi için Bkz.: Lukanov vd., 2005; Atalay, 2001; Atalay, 2007; Atasoy, 2010; Atasoy, 2019; Bayar, 2011; Özey, 2008; Özgüç, 2011; Timor, 2002.

2 Daha detaylı bilgi için Bkz.: Lukanov vd., 2005; Atalay, 2001; Atalay, 2007; Atasoy, 2010; Atasoy, 2019; Bayar, 2011; Özey, 2008; Özgüç, 2011; Timor, 2002. 


\section{ADANIN COĞRAFI KONUMU VE GENEL COĞRAFİ ÖZELLİKLERİ}

Camiguin adası (Kamiguin), Mindanao adasının kuzey kıyısına 11 kilometre uzaklıkta ve 229,8 $\mathrm{km}^{2}$ lik alana sahip küçük ama turizm açısından büyük öneme sahip olan bir volkanik adadır. Matematk konum olarak Camiguin adas $19^{\circ} 04^{\prime}-9^{\circ} 16^{\prime}$ kuzey enlemi ve $124^{\circ} 38^{\prime}-124^{\circ} 48^{\prime}$ doğu boylamı arasında yer alır. Güney Filipinlerde ve Bohol denizinde yer alan ada Mindanao adalar grubunun bir parçasıdır. Camiguin adasının kuzeyinde Bohol adası, kuzeybatısında Siquijor adası, güneyinde Mindanao ve kuzeydoğusunda Leyte ve Dinagat adaları yer alır. Adanın toplam nüfusu 90 000'i aşmaktadır ve hem başkenti hem de en büyük kenti Mambajao şehridir. Filipinler Turizm Bakanlığına göre, Camiguin adası ülkenin en ilginç 25 turizm bölgesinden biridir ve dünyanın en iyi dalış merkezleri sıralamasında 7. sırada yer almaktadır. Mambajao, Catarman, Sagay, Mahinog, Sagay ve Guinsilibon adanın en kalabalık ve en önemli yerleşim birimleridir. ${ }^{3}$ Mambajao kentinin hemen batısında yer alan Camiguin Airport adanın tek havalimanıdır. Filipinlerin 31. en büyük adası olan Camiguin'in temel geçim kaynaklarını balıkçılık, turizm, hayvancılık, ormancılık ve bitkisel üretim oluşturmaktadır. Kopra üretimi, abaküs, pirinç, mango, mısır ve bazı tropikal meyve ağaçları yaygın yetiştirilmektedir. Ada sınırları içinde üniversite yer almasa da 3-4 kolej, 70'ten fazla anaokulu, 60'tan fazla ilköğretim kurumu ve 13'ten fazla lise faaliyet göstermektedir.

Camiguin kavramının Filipinler coğrafyasında birçok anlamı ve karşılığı vardır. Çok boyutlu bir coğrafi kavram olarak Camiguin hem bir eyalet hem bir ada hem bir volkanik dağ ve hem bir yerleşmedir. Yaklaşık 20-23 km. uzunluğunda ve 14-15 km. genişliğinde olan Camiguin adasının toplam kıyı uzunluğu 60-70 km. civarındadır. Benzer şekilde adanın en büyük kenti olan Mambajao hem bir akarsu, hem bir şehir hem de bir dağ adıdır. Daha da ilginç olanı Camiguin adasında en yüksek debiye sahip olan rrmak, nüfus bakımından en büyük kent ve adanın en yüksek zirvesi aynı adı taşımaktadırlar: Mambajao.

Camiguin adasinda bulunan Tagdo, San Miguel, Tagdo, Bura, Mainit, Santo Nino, San İsidro, Cuna ve Bacnit adanın iç kesimlerinde, deniz kıyısında yer almayan en büyük yerleşmelerdir. Liong, Naasag, Benoni, Hubangon, Benhaan, Agoho, Yumbing, Bonbon, Lawigan, Catarman, Sagay, Manuyog, Balite, Cantaan, Guinsilibon, Cabuan, Maac, Mahinog, Catohugan, Tupsan, Magting, Balbagon ve Kuguita Camiguin adasının en büyük kıyı yerleşmeleridir. Camiguin adasında yıl boyunca yüksek sıcaklık ve yüksek nemlilik değerleri görülür. Adadaki yıllık sıcaklık ortalamas $126,5^{\circ} \mathrm{C}$ 'dir ve ortalama nem oranı $\% 76$ civarındadır. Yıl içinde en az yağış ocak, şubat, mart ve nisan aylarında, en çok yağış ise haziran, temmuz, ağustos ve eylül aylarında görülmektedir. ${ }^{4}$ Özetle, kışlar daha kurak, yaz ayları ise daha yağışlıdır. Bu nedenle kış ayları adada tatil yapmak için daha müsait iklim koşulları sunmaktadırlar.

Harita 2. Camiguin Adası Lokasyon Haritası

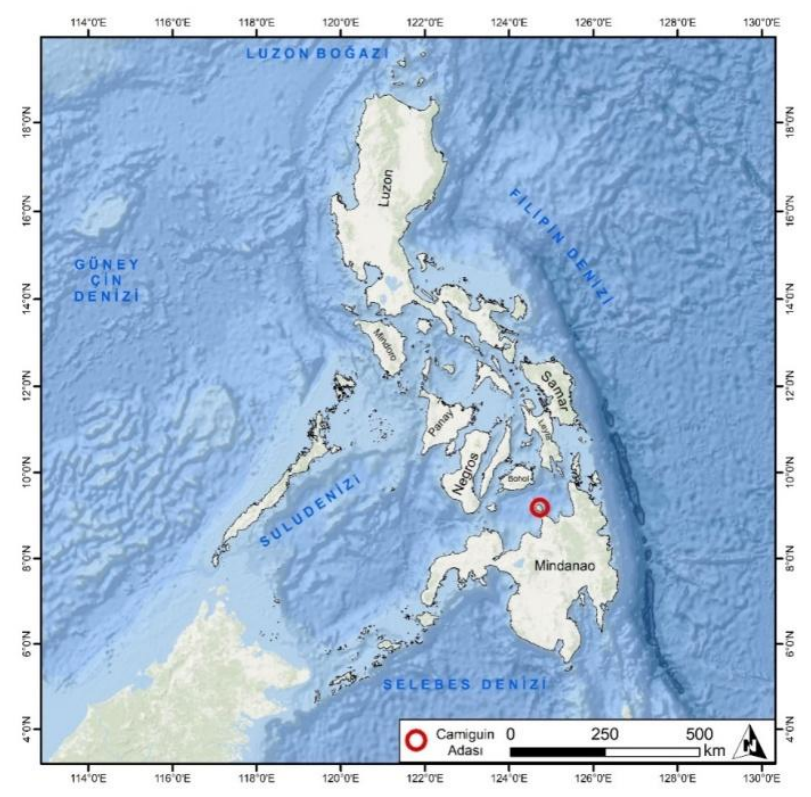

3 Daha detaylı bilgi için Bkz.: Özey, 2008; Özgüç, 2011; Bayar, 2011; Timor, 2002; http://www.camiguin.gov.ph/ (Erişim Tarihi: 03.03.2020).

4 Daha detaylı bilgi için Bkz.: Özey, 2008; Özgüç, 2011; Bayar, 2011; Timor, 2002; http://www.camiguin.gov.ph/ (Erişim Tarihi: 03.03.2020). 
Camiguin eyaleti idari yönetim bakımından 5 ilçeyi kapsamaktadır: Catarman, Guinsiliban, Mahinog, Mambajao ve Sagay. Ayrıca Camiguin eyaleti Batanes eyaletinden sonra Filipinler Cumhuriyetin en küçük eyaletidir. Camiguin adası ile komşu adalar arasında düzenli deniz ulaşımı olanaklarının bulunması hem adanın ekonomik gelişimi için hem de turizm faaliyetleri içim büyük bir avantajdır. Camiguin adasında yer alan Benoni kasabasıyla Mindanao adasında yer alan Balingoan kasabası arasında feribot ve teknelerle ile düzenli deniz ulaşımı sağlanmaktadır. Benzer şekilde Bohol adasının Jagna kasabasıyla Camiguin adasındaki Benoni kasabası arasında feribot ve teknelerle ile düzenli deniz ulaşımı sağlanmaktadır. Camiguin adasına çok yakın mesafede bulunan Beyaz adaya ve Mantigue adasına da deniz ulaşımı bağlantıları sağlanmaktadır.

Camiguin adası göl bakımından fakir bir adadır. Adanın güneydoğu kıyılarında yer alan Taguines Lagoon ve adanın kuzeybatısında yer alan Hibok-Hibok krater gölü adanın en büyük gölleridir. Küçük bir alana sahip olduğundan dolayı adada sadece kısa boylu dereler yer almaktadır. Looc, Mambojao, Alagoran ve Katihan Creek, Camiguin adasının en önemli akarsularıdır. Çok sayıda volkanik kökenli dağın bulunduğu adada en yüksek zirveler arasında Mambajao (1713 m.), Timpoong (1630 m.), Hibok-Hibok yanardağı (1332 m.), Carling (800 m.), Tres Marias (771 m.), Campana (676 m.), Guinsliban Peak (581 m.) ve Camiguin yanardağ 1 (580 m.), yer almaktadırlar.

Tablo 1. Camiguin Adasının Başlıca Özellikleri

\begin{tabular}{|c|c|}
\hline $\begin{array}{l}\text { Yer Aldığı Adalar Grubu: } \\
\text { Mindanao adalar grubu }\end{array}$ & $\begin{array}{l}\text { Toplam Nüfus: } \\
90000 \text { kişi }\end{array}$ \\
\hline $\begin{array}{l}\text { Yer Aldığı Eyalet: } \\
\text { Camiguin }\end{array}$ & $\begin{array}{l}\text { Aritmetik Nüfus Yoğunluğu: } \\
391 \mathrm{kişi} / \mathrm{km}^{2}\end{array}$ \\
\hline $\begin{array}{l}\text { Yüzölçümü: } \\
229,8 \mathrm{~km}^{2}\end{array}$ & $\begin{array}{l}\text { En Büyük Yerleşmeler: } \\
\text { Tagdo, San Miguel, Tagdo, Bura, Mainit, Santo Nino, San İsidro, Cuna, } \\
\text { Bacnit, Liong, Naasag, Benoni, Hubangon, Benhaan, Agoho, Yumbing, } \\
\text { Bonbon, Lawigan, Catarman, Sagay, Manuyog, Balite, Cantaan, Guinsilibon, } \\
\text { Cabuan, Maac, Mahinog, Catohugan, Tupsan, Magting, Balbagon ve Kuguita }\end{array}$ \\
\hline $\begin{array}{l}\text { En Yüksek Nokta: } \\
\text { Mambajao (1713 m.) }\end{array}$ & $\begin{array}{l}\text { En Uzun Akarsu: } \\
\text { Looc ve Mambajao }\end{array}$ \\
\hline $\begin{array}{l}\text { Matematik Konum: } \\
9^{\mathrm{o}} 04^{\prime}-9^{\circ} 16^{\prime} \text { kuzey enlemi ve } \\
124^{\circ} 38^{\prime}-124^{\circ} 48^{\prime} \text { doğu boylamı. }\end{array}$ & $\begin{array}{l}\text { En Büyük Göl: } \\
\text { Taguines Lagoon }\end{array}$ \\
\hline Milli Park veya Koruma Alanı: & $\begin{array}{l}\text { En Büyük Kent: } \\
\text { Mambajao }\end{array}$ \\
\hline
\end{tabular}

\section{ADANIN TURIZM POTANSIYYELI}

Ülkenin ikinci en küçük eyaleti konumunda olan Camiguin, hem karada hem de deniz içindeki flora ve fauna çeşitliliği ile gerçek bir doğa hazinesidir. Yüzlerce doğal çekiciliğe sahip olan ada volkanları, şelaleleri, yayları, milli parkları, plajları, endemik türleri, akarsu vadileri, mağaraları, kaplıcaları, dalgıç merkezleri ve mercan kayalıkları ile her yıl binlerce yabancı turist tarafindan ziyaret edilmektedir. Ada etrafindaki mercan kayalıkları yüzlerce balık türü barındırmaktadır ve bu el değememiş ekolojik ortam devletin koruması altındadır. Plaj turizmi, dağcılık, adrenalin, trekking ve dalgıçlık sevenler için Camiguin adası gerçek bir ekolojik cennettir. Dünyanın hiçbir yerinde görülmeyip sadece Camiguin adasında görülen en ünlü endemik türlerin başında bir fare türü olan "Bullimus gamay", kemirgen bir sıçan türü olan "Apomys camiguinensis", bir papağan türü olan "Loriculus camiguinensis" ve bir kurbağa türü olan "Oreophryne nana" gelir. Zoolog ve bilim adamlarına göre, adada 54 çeşit kuş ve 24 çeşit memeli yaşamaktadır ve bunların bir bölümü dünyada başka hiçbir yerde bulunmaz.

Camiguin adasında çok sayıda sıcak ve soğuk şifalı su kaynağı ve çok sayıda kaplıca tatil yeri vardır. Yerel halk bu yer altı kaynakları sayesinde yapay havuzlar, piknik alanları ve tatil merkezleri inşa etmişlerdir. Böylece her 
kaynak noktasının yakın çevresinde en az 4-5 turistik tesis ortaya çıkmıştır. Özellikle bunaltıcı sıcaklıkların yaşandığı günlerde bu soğuk havuzlar serinleme ve rahatlama görevi üstlenerek hem yerli hem de yabanc1 turistleri cezbetmektedir. Çok sayıda turist çekem bu tatil merkezlerine birkaç örnek verelim. Catarman kasabasının kuzeyinde Looc vadisinde serin sularıyla ünlü "St. Nino Cold Spring" tatil merkezi yer alır. Adanın güney kesimlerinde Sagay kasabasının hemen doğusunda havuzlarıla ve su parklarıyla ünlü "Tubod Cold Spring" yer alır. Adanın kuzeybatı kıyılarında Bonbon kasabasının kuzeyinde ve Camiguin yanardağının hemen batısında "Tangub Hot Spring" tatil merkei yer alır. Sabang plajına, Camiguin yanardağına ve Camiguin View Deck'e yakın olması Tangub tatil merkezinin önemini daha da arttırmaktadır. Camiguin adasının batı kesimlerinde Lawigan kasabasının hemen doğusunda şifalı suları ve su sporları ile meşhur olmuş "Bura Soda Water Swimming Pool" yer almaktadır. Camiguin adasının orta kesimlerinde Mambajao vadisinde ve Katibawasan Şelalesinin bulunduğu yörede Sa-ay Gold Spring yer alır. Mambajao kentinin güneybatısında ise şifalı sıcak sularıyla ünlü Ardent Kaplıcaları yer alır. Camiguin adasının doğu kesimlerinde Benhaah kasabasının hemen güneyinde daha küçük çaplı ve daha az popüler olan "Macao Cold Spring" yer almaktadır. Özetle, Camiguin adası deniz tatili, güzel plajları ve dalgıçlık merkezleri kadar kaplıca tesisleri ve termal tatil köyleri ile de ünlüdür.

Tablo 2. Camiguin Adasının Başlıca Turizm Çekicilikleri ${ }^{5}$

\begin{tabular}{|c|c|c|}
\hline Hibok-Hibok Volcano Observatory & Ardent Hot Springs & Katibawasan Şelalesi \\
\hline Giant Clam Sanctuary & Guiob Church Ruins & Mantigue Island \\
\hline Tangub Hot Spring Resort & Binangawan Şelalesi & Tuasan Şelalesi \\
\hline Macao Cold Spring & Kabila White Beach & Taguines Lagoon Gölü \\
\hline The Soda Water Swimming Pool & Sunken Denizaltı Mezarlığ & Hibok-Hibok Yanardağ1 \\
\hline Tiki Hut Stunning Ocean View & Hibok-Hibok Krater Gölü & Agohay Beach \\
\hline Puesta Del Sol Beach Bungalows & Camiguin Beefarm Bistro & Mambajao Yanardağı \\
\hline Camiguin Seaside Lodge & Chan Lookout Point & The Blue Lagoon \\
\hline Camiguin Aviation Sightseeing & Marianita's Cottages & Sabang Beach \\
\hline Mahinog Ostrich Breeding Farm & Mambajao Beach Resort & Camiguin Yanardağ 1 \\
\hline San Miguel Parish Church & Island Nature Spa & My Hiding Place \\
\hline Pamonglo Cold Springs & Roldan'S Beach Resort & Jello's Sea Cottages \\
\hline Giant Clams Sanctuary \& White Beach & Knight's of Columbus Park & Macao Spring \\
\hline CPSC Catarman Pavement Drier & Mantigue Island Cottage & Katunggan Park \\
\hline Bura Soda Water Swimming Pool & Golden Hart Farm Lot & Sa-ay Cold Spring \\
\hline Turtle'S Nest Beach Cottage & Camiguin View Deck & Tubod Cold Spring \\
\hline Marianita's Cottages Plaj1 & Algen's Dive Resort & St. Nino Cold Spring \\
\hline Cibila Giant Clam Sanctuary & Moro Watch Tower & Mambajao Camisi \\
\hline
\end{tabular}

Tablo 2'de de görüldüğ̈̈ gibi şelaleler, mağaralar, plajlar, kaplıca merkezleri, spor ve kültür tesisleri, kıy1 adacıklar, rekreasyon alanları, şifalı su kaynakları, mercan oluşumları, lagün gölleri ve volkanik oluşumlar Camiguin adasının en önemli turizm çekiciliklerini oluşturmaktadırlar. Ada genelinde doğal turizm çekiciliklerin sayısı tarihsel-kültürel turizm çekiciliklerin sayısından çok daha fazla olduğu Tablo 2'de de görülmektedir. Aşağıdaki satırlarda Camiguin adasında yer alan başlıca turizm çekicilikler özetlenerek açıklanmıştır;

5 Daha detaylı bilgi için bakınız: https://www.agoda.com/tr, https://www.hotelplanner.com/, https://www.booking.com/, https://www.trivago.com/, https://www.tripadvisor.com/ve https://www.expedia.co.uk/ (Erişim Tarihi: 03.03.2020). 
- Kamiguin Adası Volkanları: Camiguin adası volkanik kökenlidir ve ada sınırları içinde birçok volkanik dağ ve 4 genç stratovolkan yer almaktadır. Yanardağları arasında en aktif, en tehlikeli ve en yüksek olanlar Mambajao (1713 m.) ve Hibok-Hibok (1332 m.) volkanıdır. Hibok-Hibok yanardağının son patlaması 1953 yılında gerçekleşmiştir. Hibok-Hibok yanardağının son 200 yılda gerçekleştirdiği 5 patlama sonucunda volkan konisinde 3 krater oluşmuştur. Adanın orta kesimlerinde yer alan Mambahao (1552 m.), adanın güney kesiminde yer alan Guinsiliban $(581 \mathrm{~m}$.), ayrıca Timpoong ve Butay Kamiguin adasının diğer önemli yanardağlarıdır. Bunların dışında volkanik kraterlere ve kalderalara sahip olan diğer dağlar arasında Campana, Minocol, Tres Marias, Carling, Tiban ve Piakong gösterilebilir. 1949 yılında, Hibok-Hibok yanardağının gerçekleştirdiği büyük patlama sonucunda 79 kişi hayatını kaybetmiş. 4 Aralık 1951 tarihinde meydana gelen bir başka patlamada ise en az 1000 kişinin öldüğü tahmin edilmektedir. Lav akıntıları, zehirli gazlar ve piroklastik malzemeler, yaklaşı $19 \mathrm{~km}^{2}$ lik arazinin tahrip edilmesine yol açmıștır.1951 yılından sonra binlerce aile adayı terk etmiș ve Kamiguin adası önemli miktarda nüfus kaybetmiştir. Özetle volkanik dağlar Kamiguin adasındaki turizm faaliyetleri için hem bir avantaj hem bir dezavantajdır.

- Katibawasan Şelalesi (Katibawasan Falls): Katibawasan şelalesi (Katibawasan Falls) Hibok-Hibok yanardağının hemen güneydoğusunda ve Mambajao kasabasının yaklaşık $5 \mathrm{~km}$. güneybatısında yer almaktadır. Deniz seviyesinden yaklaşık 320 metre yükseklikte yer alan şelalenin yüksekliği 76 metredir. Çok çarpıcı bir görünüme sahip olan şelalenin etrafında eğrelti otları ve orkideler yaygın olarak yetişir. Katibawasan şelalesi Kamiguin adasının en çok ziyaret edilen doğal turizm çekiciliklerin başında gelir. Şelale sularının düştügü yerde serinleme ve yüzme imkânları sunan küçük bir doğal havuz yer almaktadır. Hibok-Hibok yanardağını ziyaret eden dağcılar ve turistler mutlaka bu şelaleyi de görmelidirler.

- Tuasan Şelalesi (Tuasan Falls): Katarman kasabasının yaklaşık 6 km kuzeydoğusunda ve Looc irmağ1 üzerinde yer alan Tuasan Şelalesi turistlerin ilgisini çeken bir başka doğal güzelliktir. Katibawasan şelalesi kadar yüksek ve güzel olmasa da ilginç ve güzel bir görünüm sergilemektedir. Looc ırmağının oluşturduğu güzel vadi trekking yapmak, piknik veya doğa gözlemleri için ideal manzaralar sunmaktadır.

- Binangawan Şelalesi (Binangawan Falls): Camiguin adasının güneybatısında Sagay Kasabasının hemen doğusunda bir başka küçük şelale olan Binangawan şelalesi (Binangawan Falls) yer almaktadır. "Bangaw"-yerel lehçede "gökkuşağı" anlamına gelir. Binangawan şelalesi güneş ışınlarının oynamaları ve renkli yansımaları sonucunda ortaya çıkan büyüleyici gökkuşağı sayesinde adını almıştır. Sagay veya Bonbon kasabalarından yola çıkan turistler tropikal ormanları kat ederek en geç 2 saat içinde bir patika yolunu takip ederek bu şelaleye ulaşabilirler.

- Ardent ve Tangoub Kaplıcaları (Ardent and Tangoub Hot Springs): Tektonik hareketliliğin ve yanardağ faaliyetlerinin çok aktif olduğu adada birçok şifalı termal kaynak yer almaktadır. Ardent Kaplıcaları ve Tangoub Kaplıcaları adanın en ünlü termal merkezleridir. Hibok-Hibok dağının yakınlarında bulunan Ardent Kaplıcaları, Camiguin adasının en popüler ve en meşhur olanıdır. Basamaklar ve küçük şelaleler oluşturan sıcak sular 6 ayrı havuzda toplanır. En üstteki havuz en sıcak olup su sicaklığı yaklaşık $40^{\circ} \mathrm{C}$ 'dir. Suyun sıcaklığı alt havuzlara giderken azalmaktadır, bu nedenle an alttaki son havuzun sicaklığ 1 en düşüktür. Kaplıcayı ziyaret eden turistler böylece istedikleri sıcaklıkta havuzu seçebilme ve istedikleri ortamda rahatlama ve dinlenme firsatlarına sahiptirler. Bölgede küçük çaplı yeme-içme yerleri olduğu gibi kiralık kulübeler ve odalar da vardır. Mambajao kentinin güneybatısında Mambajao 1rmağı havzasında yer alan Ardent Kaplıcaları Hibok-Hibok dağına tırmanan dağcıların ve meraklı turistlerin öncelikli dinlenme yerlerin başında gelir.

- Beyaz Ada (White Island): Bohol denizinin berrak turkuaz sularıyla çevrili olan issız Beyaz Ada (White Island) Mambajao kentinin batısında, Yumbing ve Agoho kasabalarının hemen kuzeyinde yer almaktadır. Dünyaca ünlü beyaz kumsalları ve nefes kesen güzelliği ile Beyaz Ada kıyılarından bakıldığında HibokHibok volkanına ve Camiguin adasına inanılmaz panoramik manzaralar sunmaktadır. Hiçbir bitki ve ağaç barındırmayan, hiçbir bina veya bakkal barındırmayan bu issız ada kumullardan oluşmakta ve gel-git genliğine bağlı olarak bazen su altına gömülmekte bazen ise su yüzeyine çıkmaktadır. Hiçbir turistik

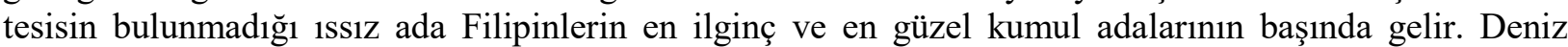
akıntılarının biçimlendirdiği bu ada okyanus suların etkisiyle farklı şekiller alarak sürekli dış görünümünü değiştirmesiyle ünlüdür. Yumbing ve Agoho kasabalarından veya Mambajao kentinden karalanacak teknelerle bu adaya kolaylıkla ulaşılır.

- Sunken Denizaltı Mezarlığı (Sunken Cemetery): 1871'de Valken yanardağının patlaması sonucunda, Katarman şehrinin kıyı bölgesi denizin içine gömülmüş ve bazı araziler ile birlikte Sunken Mezarlığı 
(Sunken Cemetery) da deniz suları altında kalmıştır. Bonbon Köyü yakınlarındaki bu yerel Katolik Mezarlığı bugün Sunken Batık Hristiyan Mezarlığı olarak dalgıçların ve meraklı turistlerin ilgisini çekmektedir. Sunken Denizaltı Mezarlığını işaretlemek için, 1982 yılında uzaktan dahi görülebilen büyük ve gösterişli bir haç inşa edilmiştir. Bugün bu ilginç mezarlık, bir yandan adanın volkanik geçmişini turistle hatırlatmaktadır diğer yandan da mezarlığın etrafındaki zengin deniz suları ile dalgıçlar için ilginç görünümler sunmaktadır. Dev istiridyeler ve eski mezarlığın her yerine dağılmış su altındaki mezar taşları meraklı dalgıçların ilgisini çekmeye devam etmektedir.

- Mantigue Adası (Mantigue Island): Camiguin adasına gelen yabancı turistler Beyaz ada ve Mantigue adasını görmeden ülkelerine pek geri dönmezler. Camiguin adasının doğu kıyılarında, Mahinog kentinin 3,5 km. doğusunda yer alan Mantigue adası 4 hektarlık bir alana sahip olan küçük ve şirin bir adadır. Adanın tamamı ve kıyıların tamamı devlet gözetiminde deniz koruma alanıdır. Bu nedenle gelişigüzel yapılaşma, avlanma, canlılara zarar verme ve balıkçılık yasaktır. Adanın topraklarında dalgıçlar ve şnorkelli yüzme dalış noktaları vardır. Filipinliler Mantigue adasına Magsaysay adını vermişlerdir. Beyaz ada 1ssız ve bitki örtüsünden yoksun iken Mantigue adası ormanlık arazilere ve birkaç küçük yerleşime sahiptir. Adanın en büyük özelliği her tarafı beyaz kumlu plajlarla ve mercan bakımından zengin masmavi berrak sularla çevrili olmasıdır. Adeta bir tropikal cennet olan Mantigue Adası kıyıları Deniz Koruma Alanı kabul edildiğinden balık avlamak yasaktır. Huzurlu ve sessiz tatil sevenler, deniz kıyısında piknik yapmayı arzulayanlar, bakir doğa ve temiz plaj arayanlar için Mantigue adası unutulmaz firsatlar sunmaktadır. Magsaysay (Mantigue) adasında ve çevresinde dalgıçlar ve şnorkelli yüzmek isteyenler için özel dalış noktaları vardır.

- Guiob Church Kalıntılart (Guiob Church Ruins-Camiguin): 13 May1s 1871 tarihinde Volcan (Kamiguin) yanardağının şiddetli patlamasından sonra, Catarman bölgesinde yer alan Guiob Katolik Kilisesi'nin büyük bir bölümü yıkılmış ve geriye sadece bazı duvarları ayakta kalmıştır. ${ }^{6}$ XVI. yüzyılda inşa edilmiş olan Guiob Katolik Kilisesi'nin bugünkü kalıntıları Camiguin adasının en önemli inanç turizm merkezi olup aynı zamanda adanın en eski dini kalıntılarıdırlar. Kilisenin ana binasının hemen arkasında, Çan Kulesi ve kadınlar manastırının eski kalıntıları yer almaktadır. Mambajao şehir merkezine 40-50 dakikalık yürüme mesafesinde yer alan bugünkü kilise kalıntıların arasında dua etmek isteyen Hristiyanlar için küçük bir şapel yer almaktadır. Guiob Katolik Kilisesi kalıntılarına giriş ücretsizdir.

- Santo Ninyo Gölleri (Sto. Niño Cold Spring): Catarman kasabası yakınlarında yer alan Santo Nino su kaynakları sıcak yaz aylarında yerli halkın en önemli ferahlama ve serinleme alanlarının başında gelirler. İki havuzun (daha büyük, 25 x $40 \mathrm{~m}$ boyutlarında) berrak, soğuk suları, sicak havalarda ideal bir serinleme ortamı oluşturduğundan birçok ziyaretçiyi cezbetmektedir. ${ }^{7}$ Yaklaşık $20^{\circ} \mathrm{C}$ sıcaklıktaki tatlı suları gerçekten ferahlatıcıdırlar. Serin su kaynakları aileler ve çocuklar için olduğu kadar yabancı turistler için de eğlenme ve yüzme olanakları sunmaktadırlar. Ada yerleşmelerini birbirine bağlayan anayoldan Catarman kasabasından Looc kasabasına ilerlerken Looc 1rmağına paralel giden yolda adanın iç kesimlerine ilerlerken karşımıza Santo Ninyo kasabası çıkacaktır. Looc ile Santo Ninyo kasabaları arasında sadece $2 \mathrm{~km}$. mesafe vardır. İşte bu küçük Santo Ninyo kasabasında havuzlarıyla ve piknik kulübeleriyle meşhur şifalı su kaynakları karşımıza çıkmaktadır. Catarman kasabasının 4 km. kuzeyinde yer alan Catarman Coral Dive Resort Santo Ninyo kasabasındaki havuzları ziyaret edenlerin ilk uğrak yeridir.

- Bura Sodalı Yüzme Havuzu (The Soda Water Swimming Pool in Camiguin): Camiguin adasının batısında yer alan ve özel olarak yapılmış olan Bura Soda Sulu Yüzme Havuzu, tüm Filipinler'de türünün ilk örneğidir. Adadaki turistik mekânların en ilginç olanıdır ve 2007 yılında hizmete açılmıştır. Keyifli zaman geçirmek, dinlenmek ve yüzmek için XXI. yüzyılın başında böylesine ilginç bir havuz yapılmıştır. ${ }^{8}$ Catarman kasabası yakınlarında yer alan bu sıra dışı havuz her yıl binlerce yerli ve yabancı turist tarafından ziyaret edilmektedir.

Camiguin adası küçük yüzölçümüne rağmen Filipinlerin en yüksek otel yoğunluğuna sahip adalardan biridir. Adanın tamamında 100 'den fazla otel, pansiyon, villa ve hostel gibi konaklama tesisi vardır. Sahil otelleri, termal otelleri, dağ otelleri, aile otelleri ve kent otelleri adanın en yaygın konaklama tesislerini oluşturmaktadırlar. Camiguin adasında her gelir grubuna ve her bütçeye uygun bir konaklama tesisi mutlaka

\footnotetext{
6 Bakını: http://www.phtourguide.com/guiob-church-ruins-in-camiguin/ ve https://www.wonderingwanderer.com/guiob-church-ruinscamiguin/ (Erişim Tarihi: 03.03.2020).

7 Bakınız: http://www.phtourguide.com/sto-nino-cold-spring/ (Erişim Tarihi: 03.03.2020).

8 Bakını: http://www.phtourguide.com/soda-water-swimming-pool-in-camiguin/ (Erişim Tarihi: 03.03.2020).
} 
bulunur. Lüks 5 yıldızlı otellerin yer almadığı Camiguin adasında 20'den fazla yüksek kaliteli konaklama tesisi hizmet vermektedir. Camiguin adasında yer alan en popüler ve en kaliteli konaklama tesislerin başında "Tiki Hut Stunning Ocean View", "Bintana Sa Paraiso", "Dreamland Beach Resort", "Paras Beach Resort", "Mountain View Cottages - Camiguin", "Balai sa Baibai", "Somewhere Else Boutique Resort", "Nouveau Resort" ve "Camiguin Volcano Houses" gibi komforlu turistik tesisler gelir.

Tablo 3. Kamiguin Adasının Başlıca Otelleri ve Konaklama Tesisleri ${ }^{9}$

\begin{tabular}{|c|c|c|}
\hline Villa Paraiso Resort \& Waterpark & TheView Camiguin & Laguna Loft \\
\hline Sun's House Mambajao & Paco's Garden Cottages & Nautilus Cottages \\
\hline Nypa Style Resort Camiguin & Pilgrim Beach Resort & Pocahontas Hostel \\
\hline La Casita Camiguin & Bucana Traveler's Inn & Casa De Cutab \\
\hline Islet Beach Resort & Algen's Dive Resort & Casa Tabamo \\
\hline Abner's Place And Pension House & Kokomo Dive Resort & Nouveau Resort \\
\hline Anito Mambajao Homestay & Ferrabrel Beach Resort & Linda Home Stay \\
\hline Bahay Bakasyunan Sa Camiguin & Cabua-An Beach Resort & Villa Corrales \\
\hline Roldan's Beach Cottages & Villa Felipa Transient Lodge & Little Bridges \\
\hline Yvonne Cottages and Mini Golf & Myrna's Bamboo Cottages & Miranda Homestay \\
\hline Morning Glory Beach Cottages & Beach House Resort & Philmany Apartments \\
\hline Somewhere Else Boutique Resort & Bahandi Beach Resort & Mabini Lodge \\
\hline YSLA Beach Camp and Eco Resort & Tambulian House for Rent & Amaya Hotel \\
\hline Paradise Island Apartelle & Medano Island Resort & Seascape Resort \\
\hline Mountain View Cottages - Camiguin & Lansang Residencies & Balai sa Baibai \\
\hline Sabacajan Beach \& Cottages & Camiguin Chumz Travelodge & Caves Dive Resort \\
\hline Camiguin White Island Beach Resort & Hidden Suites Camiguin & Bat Tree Cottages \\
\hline Myrna's Burger \& Homestay & Sacred Nest Homestay & Casa Melsol \\
\hline July's Haven Seaside Pension & Paras Beach Resort & Lanzones Cabana \\
\hline Tiki Hut Stunning Ocean View & Kurma Eco Beach Lodge & B Villas Hotel \\
\hline Golden Sunset Beach Club & Terrasse Beach Resort & Paguia Cottages \\
\hline Turtle Beach Cottage Camiguin & Veance Travellers Inn & Carmen's Haven \\
\hline Sunset Paradise Lodge at the Sea & Dreamland Beach Resort & Villa San Tiago \\
\hline Dayo Beach Resort and Cottages & Bintana Sa Paraiso & Rd Cottages \\
\hline R. Blest Viajeros House Rentals & Janca Vacation Rentals & Jumawid Homestay \\
\hline Kinghorn Garden House Resort & Creek Traveler Cottages & C-Side \\
\hline Camiguin Volcano Houses & La Casita 2 Camiguin & Casa Roca Inn \\
\hline Camiguin Highland Resort & Taylor's Country Homes & Balai sa Baibai \\
\hline Camiguin Island Golden Sunset Beach & Bintana Sa Paraiso & Lanzones Cabana \\
\hline$\underline{\text { Bahay Bakasyunan Sa Camiguin }}$ & Mountain View Cottages & Puesta Del Sol \\
\hline Camiguin Volcan Beach Eco Retreat & Tongatok Cliff Resort & Casa Absuelo \\
\hline Bintana sa Paraiso Binunsaran & Dreamland Beach Resort & Casa Esperanza \\
\hline
\end{tabular}

9 Daha detaylı bilgi edinmek için Bkz.: https://www.agoda.com/tr, https://www.hotelplanner.com/, https://www.booking.com/, https://www.trivago.com/, https://www.tripadvisor.com/ ve https://www.expedia.co.uk/ (Erişim Tarihi: 03.03.2020). 


\section{SONUÇ VE DEĞERLENDİRME}

Çarpıcı şelaleler, olağanüstü güzellikteki ıssız plajlar, soğuk su kaynakları, güzel volkanik dağlar, sıra dışı havuzlar, renkli mercanlar, şifalı kaplıcalar ve ilginç endemik canlılar Camiguin adasına her yıl binlerce turistin gelmesine neden olmaktadır. Filipinlerin en güzel ve en ilginç adalarından biri olan Camiguin, volkanik dağlar ile sessiz ve sakin deniz tatili tercih edenlerin öncelikli seçenekleri arasında gelmektedir. Bohol denizin incisi olan ada, XXI. yüzyılda büyük bir turizm atağı gerçekleştirerek hem turistik tesis sayısını hem de gelen yabancı turist sayısını ciddi oranda arttırmayı başarmıştır.

Camiguin adasının başlıca turizm avantajları şöyle özetlenebilir;

- Camiguin küçük, kompakt, kolay gezilebilen, ulaşım sorunları olmayan ve her yere kolaylıkla ulaşılabilen bir adadir.

- Mindanao, Cebu, Siquijor, Bohol, Leyte ve Negros adalarına çok yakın mesafede bulunması ve birçok adayla feribot bağlantıları olması turizm bakımından büyük bir avantaj sağlamaktadır.

- Camiguin adasında çok sayıda kaplıca merkezi, yapay yüzme havuzları, ayrıca sıcak ve soğuk şifalı su kaynakları vardır.

- Camiguin adasında hem çok sayıda hem de her bütçeye uygun otel ve konaklama tesisi vardır. Ada sinırları içinde 20'den fazla yüksek kalitede otel vardır.

- Camiguin adasında dağcıların, ekologların, coğrafyacıların, jeologların ve volkan bilimcilerin ilgisine çekebilen çok sayıda dağ ve yanardağı vardır.

- Camiguin hem endemik türleriyle hem de flora ve fauna çeşitliliği ile meraklı turistler için gerçek bir doğa hazinesidir.

- Camiguin kıyılarında yüzlerce mercan oluşumu, çok sayıda gizli koy ve çok sayıda atol yer almaktadır, tüm bunlar dalgıçlar için bulunmaz bir dalış firsatı demektir.

- Krater ve lagün gölleriyle, dar ve derin kanyon vadileriyle, beyaz kumsal plajlarıyla, yoğun tropikal ormanlarıyla Camiguin adasında her turist farklı bir cennet köşesi keşfedebilir.

- Ada sınırları içinde ulaşım, haberleşme, internet ve alt yapı sorunlarının pek olmaması,

- Yabancı turistler için adanın huzurlu ve güvenli olması, etnik çatışmaların ve terör olaylarının yaşanmamas1.

- Ada sınırları içinde çok sayıda mağara, koy, plaj, atol, şelale gibi doğal turizm çekiciliklerin olması.

Camiguin adasının en büyük turizm avantajlarından birisi küçük yüzölçümüne sahip olmasına rağmen çok çeşitli turizm olanakları, çok sayıda kaliteli konaklama tesisi ve zengin rekreasyon faaliyetlerini aynı anda sunabilmesidir. XXI. yüzyılda Camiguin adasında uygulanabilir başlıca turizm tipleri ve adayı ziyaret eden turistlerin katılabilecekleri başlıca rekreasyon faaliyetleri şunlardır: inanç turizmi, tarihsel-kültürel turizm, kırsal turizm, deniz turizmi, ekoturizm, çiftlik turizmi, mağara turizmi, sualtı dalış turizmi, botanik turizmi, yayla turizmi, tatlı su balıkçılığı, dağcılık, yamaç paraşütü, yaban hayatı gözlemciliği, deniz sörfü, bisiklet turları, kampçılık, doğa yürüyüşü (trekking), dağ tırmanışı ve sportif dalgıçlık.

\section{KAYNAKLAR}

APUAN, Dennis A. ve APUAN, Mary Jean B. (2016), "Patterns of Variations in Earthworm Density in Multivariate Landscape of Camiguin Island, Philippines", Journal of Scientific Research and Development, S.3(4), ss.118-123.

ATALAY, İbrahim (2001), Resimli ve Haritalı Dünya Coğrafyası, İnkılâp Kitabevi Yayını, İstanbul.

ATALAY, İbrahim (2007), Kıtalar ve Ülkeler Coğrafyası, META Basım Yayınları, İzmir.

ATASOY, Emin (2010), Kıtalar ve Ülkeler Coğrafyası, Ezgi Kitabevi Yayınları, Bursa.

ATASOY, Emin (2019), Kültür Coğrafyası ve Etnocoğrafyanın Temelleri, Değişim Yayınları, İstanbul.

BAYAR, Sevilay (2011), Filipinler Ülke Raporu, T. C. Başbakanlık Dış Ticaret Müsteşarlığı İhracatı Geliştirme Merkezi Yayını, Ankara. 
DÜZYOL, Tamer (2016), “Filipinler”, Dünya Siyasetinde Doğu Asya (Ed. İsmail Ermağan), Nobel Yayınları, Ankara.

GEORGIEV, P. (2005), “Filipinite i Evraziyskata Diga na Nestabilnost”, Spisanie "Geopolitika”, Broy 6, Sofya.

LAKOST, İ. (2005), Geopolitiçeski Reçnik na Sveta, Izdatelska Kaşta Trud, Sofya.

LAVROV, S. B. ve Kaledin, N. V. (2003), Ekonomiçeskaya, Sotsialnaya i Politiçeskaya Geografiya Mira: Regioni i Strani, İzdatelstvo Gardariki, Moskova.

LOPEZ, Mellie Leandicho (2006), A Handbook of Philippine Folklore, Quezon City, The University of the Philippines Press, Manila.

LUKANOV, A., Bojinov, N., Dimitrov, S., (2005), Stranite v Sveta 2005-2006, İzdatelstvo Gloriya Palas, Sofya.

MANALO , Jazztin Jairum P. (2017), "Relevance of Sustainable Tourısm in The Philippines: Case of Boracay Island And Puerto Princesa City", International Journal of Information Research and Review, S.4(1), ss.3558-3562.

MANUELA, Wilfred S. ve De VERA, Manuel J. (2015), "The Impact of Government Failure on Tourism in The Philippines", Transport Policy, S.43(C), ss.11-22.

ÖZEY, Ramazan (2008), Asya Coğrafyası, Aktif Yayınları, İstanbul.

ÖZGÜÇ, Nazmiye (2011), Turizm Coğrafyası: Özellikler ve Bölgeler, Çantay Kitabevi, İstanbul.

SANTOS, Romeo B. ve TOMELDAN Melanie V. (2009), "Case-Based Study of Three Tourism-Dependent Islands in the Philippines The Cases of Boracay Island", A Journal of Architecture, Landscape Architecture and the Designed Environment (Ed. Puerto Galera Aklan, Oriental Mindoro, Paawan Coron), University of the Philippines College of Architecture Press, Philippines.

SEXTON, Colleen A. (1967), Philippines in Pictures, Library of Congress Cataloging, Manila, C.1.

SHAH, Kishore ve GUPTA, Vasanti (2000), Tourism, the Poor and Other Stakeholders: Experience in Asia, Overseas Development Institute - Fair Trade in Tourism Project, University of North London, University of North London, UK.

TİMOR, Ayşe Nur (2002), Güneydoğu Asya: Özellikler, Ülkeler, Çantay Kitabevi Yayını, İstanbul.

http://www.camiguin.gov.ph/ (Erişim Tarihi: 03.03.2020).

http://www.phtourguide.com/category/camiguin/ (Erişim Tarihi: 03.03.2020).

http://www.pilipino.ru/main.php?show=place\&with=camiguin (Erişim Tarihi: 03.03.2020).

https://ru.wikipedia.org/wiki/ (Erişim Tarihi: 03.03.2020).

https://travelask.ru/questions/898085-camiguin-island (Erişim Tarihi: 03.03.2020).

https://www.agoda.com/tr (Erişim Tarihi: 03.03.2020).

https://www.booking.com/ (Erişim Tarihi: 03.03.2020).

https://www.expedia.co.uk/ (Erişim Tarihi: 03.03.2020).

https://www.hotelplanner.com/ (Erişim Tarihi: 03.03.2020).

https://www.palawandays.ru/camiguin-island-philippines (Erişim Tarihi: 03.03.2020).

https://www.sabaiasia.ru/Philippines/mindanao/camiguin-island.htm (Erişim Tarihi: 03.03.2020).

https://www.tourister.ru/world/asia/philippines/region/kamigin (Erişim Tarihi: 03.03.2020).

https://www.tripadvisor.com/ (Erişim Tarihi: 03.03.2020).

https://www.trivago.com/ (Erişim Tarihi: 03.03.2020).

https://www.wonderingwanderer.com/ (Erişim Tarihi: 03.03.2020). 